\title{
AMBIENTALISMO E CONCEPÇÕES DE RESEX, EXTRATIVISMO E CONHECIMENTO NO ICMBIO NA AMAZÔNIA LEGAL
}

\author{
Daniel Santos Menezes \\ 05daniel@gmail.com \\ Instituto Brasileiro do Meio Ambiente e dos Recursos Naturais Renováveis - MG/Brasil \\ Osmar Siena \\ osmar_siena@uol.com.br \\ Fundação Universidade Federal de Rondônia - RO/Brasil \\ Tomás Daniel Menéndez Rodríguez \\ tomasdanielm@gmail.com \\ Fundação Universidade Federal de Rondônia - RO/Brasil
}

Recebido em 13/04/2009

Aprovado em 22/10/2010

Disponibilizado em 01/08/2011

Avaliado pelo sistema double blind review

Revista Eletrônica de Administração

Editor: Luís Felipe Nascimento

ISSN 1413-2311 (versão on-line)

Editada pela Escola de Administração da Universidade Federal do Rio Grande do Sul.

Periodicidade: Quadrimestral

Sistema requerido: Adobe Acrobat Reader.

\section{INTRODUÇÃO}

O Instituto Chico Mendes de Conservação da Biodiversidade (ICMBIO), criado em 2007 a partir do desmembramento do Instituto Brasileiro do Meio Ambiente e dos Recursos Naturais Renováveis (IBAMA), é o órgão responsável por propor, implantar, gerir, fiscalizar e monitorar as Unidades de Conservação (UC's) federais (BRASIL, 2007). Esse desmembramento fez com que o ICMBIO herdasse do IBAMA parte de seus servidores, normas e também a complexidade de concepções e posturas ambientalistas do órgão de origem. Por isso, essa nova autarquia pode conter variações significativas e conflituosas quanto à compreensão ambiental, colaborando com seus objetivos ou comprometendo-os, conforme a maneira como são abordados os conflitos gerados (MENEZES; SIENA, 2010).

Entre as atribuições do ICMBIO estão as atividades de gestão das Reservas Extrativistas (RESEXs), uma categoria de UC, que também são vistas com olhares diferentes 
Ambientalismo e concepções de RESEX, extrativismo e conhecimento no ICMBIO na Amazônia Legal

por instituições, profissionais e cientistas de várias origens e concepções. As RESEXs expressam, no contexto de sua gestão, o problema da possibilidade do convívio sustentável do homem com o meio natural, bem como o grau de autonomia e validade do conhecimento tradicional para o desenho e implementação de políticas públicas.

No processo de gestão das RESEXs existe um contato freqüente entre populações tradicionais e técnicos do órgão gestor. Estes manifestam diferentes graus de ativismo e convivem com interesses envolvendo o bem-estar socioeconômico das comunidades, a preservação de suas culturas e do meio ambiente. Nessa convivência, transitam entre diversas visões ambientalistas e relações de poder entre conhecimento científico e tradicional.

Em relação ao extrativismo, tal como ocorre com as RESEXs, não há consenso sobre sua viabilidade e oportunidade. Há oposição dos conservacionistas clássicos, pois consideram este tipo de atividade falida (PÁDUA, M., 2006; OLMOS, 2007) ou oportunista, sendo o termo extrativista um rótulo utilizado para obter benefícios de políticas públicas.

É neste contexto que atuam os técnicos ICMBIO, que possuem diferentes aptidões técnicas e políticas para lidar com a complexidade da realidade, com possibilidade de serem influenciados pela formação acadêmica, assim como parece ocorrer também em relação à orientação ambientalista (MARTINEZ-ALIER, 2007; GUHA, 2000). O convívio com as normas organizacionais e com as comunidades tradicionais podem também alterar a visão desses técnicos, podendo ocorrer a migração de uma visão para a outra. É possível também que as vinculações departamentais no IBAMA, antes da lotação no ICMBIO, tenham influenciado a orientação ambientalista. Esses fatores parecem ser determinantes para a visão sobre a função de conservação das RESEXs e o tratamento dispensado ao conhecimento tradicional das populações residentes.

Diante desse quadro, a pesquisa procurou responder o seguinte questionamento: quais as vertentes do pensamento ambientalista existentes no ICMBIO e suas relações com as concepções de RESEX, concepções de extrativismo e concepções de conhecimento? Assim, a pesquisa objetivou identificar as vertentes ambientalistas e as possíveis relações entre elas e concepções de conhecimento, extrativismo e RESEXS, com foco nos técnicos de formação acadêmica superior do ICMBIO lotados na Amazônia Legal.

O ICMBIO tem como uma de suas funções a execução das políticas de uso sustentável dos recursos naturais renováveis e de apoio ao extrativismo e às populações tradicionais nas unidades de conservação federais de uso sustentável. De acordo com o Decreto $n^{\circ} 6.100$, de 26 de abril de 2007 (BRASIL, 2007a), sua estrutura engloba a administração superior, 
diretoria administrativa e órgãos específicos singulares, entre os quais duas diretorias diretamente relacionadas às UCS: a) a Diretoria de Proteção Integral (DIPI), a qual substituiu a Diretoria de Ecossistemas (DIREC) do IBAMA, está dividida em duas coordenações: a Coordenação Geral de UCs de Proteção Integral e a Coordenação Geral de Visitação Pública; o objetivo principal da DIPI é garantir a preservação da natureza, evitando ou minimizando a interferência humana nas áreas de proteção integral, uma vez que nessas só é admitido o uso indireto dos seus recursos; b) a Diretoria de UCs de Uso Sustentável e Populações Tradicionais (DIUSP), substituindo a Diretoria de Florestas (DIREF) e a Diretoria Socioambiental (DISAM) do IBAMA, com duas coordenações distintas, respectivamente, a Coordenação Geral de Florestas Nacionais (CGFN) e a Coordenação Geral de Reservas Extrativistas e de Desenvolvimento Sustentável (CGRES); as áreas coordenadas pela DIUSP visam assegurar a preservação da natureza com o uso sustentável de parcela de seus recursos naturais (BRASIL, 2007b).

$\mathrm{O}$ artigo está organizado em sete seções. Na segunda, terceira e quarta seções é realizada uma revisão da literatura sobre ambientalismo, visões do conhecimento, de RESEXs e de extrativismo. Na quinta seção são expostos os procedimentos metodológicos. Os resultados são apresentados e discutidos na sexta seção. Na sétima são enunciadas as principais conclusões.

\section{AMBIENTALISMO}

O ambientalismo, desde seus primórdios, não é um movimento uniforme, mas composto por uma diversidade de pensamentos e comportamentos. No caso brasileiro, por exemplo, Pádua, J. (1987) registrou variações do pensamento ambientalista desde suas primeiras expressões históricas, momento em que duas visões estiveram em contraste: a da Terra de Santa Cruz e a terra do pau Brasil. A primeira preocupada com o estabelecimento de uma sociedade autóctone e independente da metrópole, influenciada por uma perspectiva renascentista e romântica da natureza. A segunda, com a exploração colonial dos recursos naturais e enriquecimento da metrópole, com predomínio da visão mercantilista.

As políticas ambientais no Brasil surgiram mais tardiamente, com a celebração de um tratado internacional de proibição do comércio de penas de garças, em 1895, que evitou a extinção da espécie (PÁDUA, J., 1987). No período entre 1920 e 1970 surgiram as leis, normas e instituições voltadas para as questões ambientais: Código das Águas e Minas, o Código de Caça e Pesca, o Código Florestal, a criação dos primeiros parques nacionais, a REAd - Edição 69 - Vol. 17 - Nº 2 - maio/agosto 2011 - p. 451-479 
Ambientalismo e concepções de RESEX, extrativismo e conhecimento no ICMBIO na Amazônia Legal

fundação do Serviço Florestal Brasileiro e, posteriormente, a criação do Instituto Brasileiro de Desenvolvimento Florestal (IBDF) (DRUMMOND, 1997; RYLANDS; BRANDON, 2005).

Como movimento autoconsciente e organizado, o primeiro pensamento ambientalista ou ecologista surgiu no século XIX, em defesa da natureza intocada, dos bosques primários e dos cursos d'água (MARTINEZ-ALIER, 2007). Essa primeira expressão foi representada pelo naturalista e escritor John Muir, fundador do Sierra Club nos Estados Unidos como "Culto ao silvestre"; a segunda expressão do movimento, denominada "Evangelho da Ecoeficiência", foi iniciada pelo chefe do serviço florestal dos EUA, Gifford Pinchot, calcada nos métodos europeus de manejo florestal científico, com perspectiva utilitarista; a terceira expressão do ambientalismo organizado, o "Ecologismo dos Pobres", foi fortalecida principalmente a partir da década de 1980, com a luta de indígenas e camponeses do terceiro mundo e o movimento da justiça ambiental nos EUA (MARTINEZ-ALIER, 2007).

No contexto deste trabalho, essas três correntes são referidas, respectivamente, como Preservacionismo, Sustentabilismo e Socioambientalismo.

O preservacionismo influenciou o surgimento dos Parques Nacionais nos EUA e engloba a visão da natureza selvagem - Wilderness - e frágil, necessitando ser intocada e objeto de proteção pela humanidade (COLCHESTER, 2000; SARKAR, 2000; MARTINEZALIER, 2007). Essa vertente foi fortalecida pela Biologia da Conservação, disciplina desenvolvida a partir da década de 1960, fornecedora da base científica dessa vertente. A Biologia da Conservação defende claramente a preservação acima do uso mercantil. Os biólogos da conservação utilizam conceitos e teorias que evidenciam o ritmo acelerado do decréscimo da biodiversidade (MARTINEZ-ALIER, 2007).

Colabora também para o preservacionismo a Ecologia Profunda, que segundo Martinez-Alier (2007) traz para o interior do ambientalismo a perspectiva ecocêntrica, em oposição ao antropocentrismo. Para Pepper (2000), na Ecologia Profunda o ser humano é parte constituinte da natureza; não está acima e nem fora dela. Dessa forma, não pode arbitrar valor ao restante do mundo natural. $\mathrm{O}$ igualitarismo biológico exige que a humanidade respeite todas as formas de vida e de "não vida". Aliás, para esta corrente, tudo está em certo sentido vivo dentro de uma comunidade ecológica, fazendo parte de um todo ecológico.

O sustentabilismo aparece como a segunda corrente organizada historicamente em torno das concepções de ecoeficiência, modernização ecológica e da economia ecológica. Há preocupação com o crescimento econômico e seus impactos no meio ambiente e na saúde humana. Essa corrente teve início com os métodos de manejo florestal científico, há mais de 
cem anos, e foi fortalecida com a ação do Instituto Wuppertal na Europa, nos anos 1990, centrada no uso da tecnologia para o combate do desperdício e da poluição industrial (MARTINEZ-ALIER, 2007). Ocorrido a partir de mudanças internas, principalmente na década de 1980, o sustentabilismo constitui um desdobramento do ambientalismo, A mudança de postura sofreu a pressão da recessão européia do final dos anos 1970, que colocou o tema econômico novamente na agenda política, forçando os grupos ambientalistas a buscar um meio de conciliação entre reestruturação econômica e proteção ambiental, com o objetivo de reconquistar a credibilidade pública de seus discursos. As atividades desempenhadas pela Organização das Nações Unidas (ONU) e pela Organização para a Cooperação e Desenvolvimento Econômico (OECD) parecem ter favorecido o desenvolvimento da linguagem da modernização ecológica. O Relatório Brundtland de 1987 - Nosso Futuro Comum - produzido pela ONU popularizou o conceito de desenvolvimento sustentável (LENZI, 2006) que na visão de Hajer (1995), constitui uma declaração do paradigma da modernização ecológica.

Segundo Zhouri (2006), a visão da ecoeficiência está disseminada na Amazônia. As principais organizações não-governamentais (ONGs) em associação com o setor empresarial madeireiro desenvolveram um sistema de certificação florestal, o Forest Stewardship Council (FSC ou Conselho de Manejo Florestal), objetivando melhorar as práticas florestais mundiais. Com o apoio do Banco Mundial, a visão da ecoeficiência influenciou consideravelmente o desenho de políticas públicas regionais, com ênfase no papel do manejo florestal como atividade a ser incentivada para a Amazônia (ZHOURI, 2006).

Para Martinez-Alier (2007) a atenção da ecoeficiência, em contraposição à visão anterior, está mais no manejo sustentável dos recursos naturais e não na perda de atrativos da natureza ou valores intrínsecos. Embora seja utilizada a palavra "natureza", os termos "recursos naturais", "serviços ambientais" e "capital natural" são mais utilizados, com grande influência da economia ambiental.

O socioambientalismo, por sua vez, nos termos utilizados por Diegues (2000), é composto pelo "ecologismo social" ou "ambientalismo camponês". Martinez-Alier (2007) o concebe no âmbito da ecologia política e demonstra que em sua base estão os conflitos distributivos dos custos e benefícios da utilização ou preservação dos recursos naturais. Duas disciplinas e grupos de profissionais prevalecem nessa vertente: 1) a Ecologia Política composta por antropólogos e geógrafos do Terceiro Mundo que trabalham com a problemática rural; e, 2) a Justiça Ambiental com a presença de ativistas em direitos civis, sociólogos e especialistas em relações raciais dos EUA e África do Sul.

REAd - Edição 69 - Vol. 17 - N 2 - maio/agosto 2011 - p. 451-479 
Ambientalismo e concepções de RESEX, extrativismo e conhecimento no ICMBIO na Amazônia Legal

No âmbito do socioambientalismo existe a defesa da permanência das populações tradicionais em seus territórios e da utilização dos recursos naturais locais. Este ambientalismo passou a influenciar uma nova forma de ver a conservação e propôs a participação das comunidades tradicionais no planejamento e na gestão das atividades de conservação. No Brasil, essa participação possibilitou a inclusão da Reserva de Desenvolvimento Sustentável (RDS) no Sistema Nacional de Unidades de Conservação (SNUC) e a expansão das Reservas Extrativistas (RESEXs) (DIEGUES, 2000; SANTILLI, 2005).

Porto (2005) destaca três dimensões que colaboram na compreensão dos problemas socioambientais contemporâneos: (1) a dimensão do conhecimento e defende o desenvolvimento de abordagens integradas para superação das limitações impostas pelo modelo científico; (2) a dimensão do poder, realçando o entendimento dos problemas ambientais a partir das relações assimétricas centro-periferia; e, (3) a dimensão da ação, a exemplo das redes sociais baseadas em valores de solidariedade e respeito à natureza e aos direitos humanos.

O quadro 1 resume as informações sobre as vertentes ambientalistas discutidas. 
Ambientalismo e concepções de RESEX, extrativismo e conhecimento no ICMBIO na Amazônia Legal

\begin{tabular}{|c|c|c|c|}
\hline Características & Preservacionismo & Sustentabilismo & Socioambientalismo \\
\hline $\begin{array}{l}\text { Década de } \\
\text { expressão inicial no } \\
\text { Brasil }\end{array}$ & $\begin{array}{l}\text { Década de } 1970 \text { - Fundamentalismo } \\
\text { ambientalista e isolamento }\end{array}$ & Década de 1980 & $\begin{array}{c}\text { Década de } 1980 \text { - Ambientalismo camponês na } \\
\text { Amazônia, África e Índia }\end{array}$ \\
\hline $\begin{array}{l}\text { Fortalecimento e } \\
\text { consolidação }\end{array}$ & $\begin{array}{c}\text { Década de } 1980 \text { - Realismo e ação } \\
\text { política }\end{array}$ & $\begin{array}{l}\text { Consolidação na ECO-92 - Protocolo } \\
\text { de Kyoto }\end{array}$ & $\begin{array}{l}\text { Difusão e ascensão no Brasil, nos anos } 1990 . \\
\text { Fortalecimento na década atual }\end{array}$ \\
\hline Linha de atuação & Defesa da natureza intocada & $\begin{array}{l}\text { Defesa da exploração racional dos } \\
\text { recursos }\end{array}$ & $\begin{array}{c}\text { Defesa da mudança de paradigma na relação homem- } \\
\text { natureza, nas políticas ambientais e na distribuição de } \\
\text { recursos }\end{array}$ \\
\hline Visão econômica & $\begin{array}{c}\text { Ação de retaguarda contra o avanço da } \\
\text { economia industrial }\end{array}$ & $\begin{array}{l}\text { Ação de integração: natureza e } \\
\text { economia }\end{array}$ & $\begin{array}{l}\text { Reconhecimento e apoio à sustentabilidade no manejo } \\
\text { tradicional }\end{array}$ \\
\hline $\begin{array}{l}\text { Aspectos mítico- } \\
\text { religiosos }\end{array}$ & $\begin{array}{c}\text { Aspectos sagrados da natureza } \\
\text { (panteísmo, relatos bíblicos, tradição romana } \\
\text { franciscana) }\end{array}$ & $\begin{array}{l}\text { Crença na tecnologia e regulamentação } \\
\text { ambiental da economia }\end{array}$ & $\begin{array}{c}\text { Contribuição das culturas, mitos e religiões tradicionais - } \\
\text { busca da justiça ambiental }\end{array}$ \\
\hline $\begin{array}{l}\text { Instrumentos de } \\
\text { ação }\end{array}$ & $\begin{array}{c}\text { Utilização da coerção estatal e da } \\
\text { legislação ambiental para frear atividades } \\
\text { predatórias }\end{array}$ & $\begin{array}{l}\text { Estímulo ao desenvolvimento } \\
\text { tecnológico para a sustentabilidade }\end{array}$ & $\begin{array}{l}\text { Estímulo à democracia e autonomia das populações } \\
\text { tradicionais para decidir o destino de seus territórios e seus } \\
\text { recursos naturais }\end{array}$ \\
\hline $\begin{array}{r}\text { Disciplinas } \\
\text { fundamentais }\end{array}$ & $\begin{array}{l}\text { Ecologia (Profunda) e Biologia da } \\
\text { Conservação }\end{array}$ & $\begin{array}{l}\text { Modernização Ecológica, Ecoeficiência } \\
\text { e Economia Ambiental }\end{array}$ & Etno-Conservação, Ecologia Política e Justiça Ambiental \\
\hline $\begin{array}{l}\text { Profissionais } \\
\text { envolvidos }\end{array}$ & Filósofos ambientalistas e biólogos & Engenheiros e economistas & $\begin{array}{c}\text { Antropólogos, geógrafos, sociólogos e especialista em } \\
\text { direitos civis }\end{array}$ \\
\hline $\begin{array}{l}\text { Exemplos de } \\
\text { instituições } \\
\text { influentes }\end{array}$ & $\begin{array}{l}\text { Worldwide Fund of Nature (WWF), } \\
\text { União Mundial para a Conservação da } \\
\text { Natureza (IUCN), Nature Conservancy }\end{array}$ & $\begin{array}{c}\text { Instituto Wuppertal (Europa) Ginfford } \\
\text { Pinchot (EUA), Banco Mundial, ONU, } \\
\text { OECD, Worldwide Fund of Nature } \\
\text { (WWF) }\end{array}$ & $\begin{array}{l}\text { Conselho Nacional dos Seringueiros (CNS), Movimento } \\
\text { dos Atingidos por Barragens (MAB), Movimento dos } \\
\text { Pescadores Artesanais (MPA), Movimento dos Povos } \\
\text { Indígenas (MPI), União Mundial para a Conservação da } \\
\text { Natureza (IUCN), Rede Brasileira de Justiça Ambiental } \\
\text { (RBJA) }\end{array}$ \\
\hline
\end{tabular}

Quadro 1 - Síntese das vertentes ambientalistas.

Fonte: Menezes e Siena, 2010, p. 486.

REAd - Edição 69 - Nº 2 - maio/agosto 2011 - p. 451-479 


\section{VISÕES DO CONHECIMENTO}

Em meio às convergências e divergências entre as linhas ambientalistas, são propostas novas formas de interpretar o conhecimento - chamado por Leff (2001) de "conhecimento ambiental" - que possibilitariam uma convergência entre tradição e conservação ambiental. No conhecimento ambiental há destaque para problemática do uso do poder na ciência, que gera a imposição científica às culturas e sociedade locais, sem a devida observação e respeito às suas estruturas e funções, processo denominado de "colonização dos saberes" (SANTOS, 2005) ou "imperialismo verde" (GUHA, 2000).

Para Santos (2005) existem hoje duas vertentes que debatem a questão da pluralidade da ciência.

A primeira, interna à ciência, questiona o caráter monolítico do cânone científico e debate a relevância epistemológica, sociológica e política da diversidade interna da ciência. Trata-se, no fundo, de questionar os pressupostos da neutralidade, explicitando fatores interferentes no processo de escolhas de temas, problemas teóricos, metodologias, linguagens, formas de argumentação, o relacionamento dos cientistas com seus financiadores, com seus pares e com o Estado, com os interesses econômicos ou públicos. Interroga-se, por fim, a autonomia das atividades científicas, relacionando-a ao contexto de suas existências. Assim, para Santos essa realidade é o mais recente das chamadas Guerras da Ciência, que pode ser entendida como uma tentativa de reafirmação estruturante, um restabelecimento e policiamento de fronteiras entre domínios de saber.

A segunda vertente é contrária ao exclusivismo epistemológico da ciência. Ocupa-se das relações entre ciência e outros conhecimentos, a pluralidade externa da ciência. Discute-se a questão da demarcação da ciência com outros conhecimentos tidos por não científicos, ou irracionais, incluídas as artes, as humanidades, a religião e as várias versões não-reflexivas da relação com o mundo. Diferentes modos de conhecer terão, assim, diferentes resultados ou impactos sobre a própria realidade (SANTOS, 2005).

Para Leff (2001), todo o conhecimento humano sobre o mundo e as coisas tem estado condicionado ao contexto geográfico, ecológico e cultural no qual se produz e reproduz uma determinada formação social. As práticas produtivas resultaram em percepções e conjuntos de técnicas específicas para apropriação social da natureza e transformação do meio. Nesse processo, a partir da capacidade simbólica do homem também se desenvolveu a sua capacidade de abstração, possibilitando-lhe estabelecer relações entre as coisas. A geometria,

REAd - Edição 69 - Nº 2 - maio/agosto 2011 - p. 451-479 
por exemplo, surgiu nas sociedades agrícolas com a necessidade de racionalizar a produção da terra por um sistema de medições.

Rohde (1996) propôs outra classificação do conhecimento ambiental: a postura anarquista coloca a Teologia, o senso comum e o conhecimento tradicional nos mesmos patamares da ciência; a segunda classe aborda um posicionamento pós-normal, um deslocamento dos termos kuhnianos (KUHN, 2006) de normalidade - originalmente restrito ao ambiente científico - para a realidade, deslocando o conceito de disciplinas para focalizar em questões científicas; a terceira classe proposta é o posicionamento unificador sistêmico, uma visão aplicativa da teoria dos sistemas, segundo a qual o planeta terra é visto como um sistema único; e, o último posicionamento proposto por Rohde é um paradigma conjuntivo que considere a Natureza-Sociedade, superando o cartesianismo disjuntivo, produzindo uma nova articulação jurídico-normativo (ética) e um novo fundamento para a educação ambiental.

Neste trabalho, adota-se a tipologia de concepções de ciência discutida por Leff (2001), onde se distinguem quatro visões do conhecimento: anarquista: situa qualquer conhecimento no mesmo patamar da ciência, com a mesma validade e legitimidade; dialógica (ou saber ambiental): corresponde à proposta de um diálogo entre ciência e saber, tradição e modernidade e contempla a internalização da dimensão ambiental nos paradigmas econômicos, instrumentos de planejamento e instituições que sustentam a racionalidade produtiva emergente; e, científica pura: constituída por campos específicos do conhecimento, regidos por critérios lógico-matemáticos, tendo o método experimental como o elo e legitimação de diversos tipos de conhecimento.

O quadro 2 apresenta uma classificação de tipos de conhecimento. 
Ambientalismo e concepções de RESEX, extrativismo e conhecimento no ICMBIO na Amazônia Legal

\begin{tabular}{|c|c|}
\hline Conhecimento & \\
\hline $\begin{array}{l}\text { Anarquista } \\
\text { (ou relativista) }\end{array}$ & $\begin{array}{l}\text { - anarquismo ou relativismo epistemológico; } \\
\text { - qualquer opinião ou argumento é tão válido e legítimo quanto toda teoria científica no } \\
\text { campo do conhecimento; } \\
\text { - desmoronamento do racionalismo como via para a verdade, a justiça e o progresso; } \\
\text { - vontade anarquizante ou democratizante para flexibilizar e relativizar o conhecimento; } \\
\text { - gestão participativa para o desenvolvimento sustentável; } \\
\text { - pressuposto de nenhuma garantia para que a ética, o método e a razão científica } \\
\text { desemboque de maneira natural e incontestável para o bem natural. }\end{array}$ \\
\hline $\begin{array}{l}\text { Saber ambiental } \\
\text { (ou dialógica) }\end{array}$ & $\begin{array}{l}\text { - o conhecimento não constitui um discurso homogêneo para ser assimilado pelas } \\
\text { diversas disciplinas científicas; } \\
\text { - não emerge de uma reorganização sistêmica dos conhecimentos atuais; } \\
\text { - não se refere a uma articulação das ciências e especialistas para buscar a integração de } \\
\text { recortes selecionados da realidade no estudo dos sistemas sócio-ambientais; } \\
\text { - rompe o círculo "perfeito" das ciências, a crença numa idéia absoluta e num } \\
\text { conhecimento unitário; } \\
\text { - abre-se para a dispersão do saber e para a diferença de sentidos existenciais; } \\
\text { - estabelece um diálogo entre ciência e saber, tradição e modernidade; } \\
\text { - propõe a revalorização de um conjunto de saberes sem pretensão de cientificidade; } \\
\text { - problematiza o conhecimento para refuncionalizar os processos econômicos e } \\
\text { tecnológicos, ajustando-os aos objetivos de equilíbrio ecológico, justiça social e } \\
\text { diversidade cultural; } \\
\text { - incorpora novos saberes, diferentes ordens de materialidade e novas matrizes de } \\
\text { sentido, e; } \\
\text { - impulsiona novas estratégias conceituais para construir uma nova racionalidade } \\
\text { teórica, social e produtiva. }\end{array}$ \\
\hline $\begin{array}{l}\text { Interdisciplinar } \\
\text { (ou sistêmico) }\end{array}$ & $\begin{array}{l}\text { - internalização de uma dimensão ambiental dentro dos paradigmas econômicos, } \\
\text { instrumentos de planejamento e instituições que sustentam a racionalidade produtiva } \\
\text { emergente; } \\
\text { - integração de diferentes ramos do conhecimento científico e técnico em torno de um } \\
\text { objetivo comum; } \\
\text { - método e prática para produção de conhecimentos e integração operativa na } \\
\text { explicação e resolução de problemas complexos; } \\
\text { - depara-se com a impossibilidade de generalizar os objetos científicos e os campos de } \\
\text { produção do conhecimento, bem como de aplicar um método totalizador e geral; } \\
\text { - ótica insuficiente para atender à demanda de conhecimentos colocada pela } \\
\text { problemática ambiental; e, } \\
\text { - no campo ambiental a visão é holística e integradora do desenvolvimento, mas não } \\
\text { abrangeu a especificidade dos processos materiais e simbólicos que o constituem. }\end{array}$ \\
\hline Pura (ou positivista) & $\begin{array}{l}\text { - a ciência vista como um campo neutro, formado por diversas apreensões, noções e } \\
\text { articulações teóricas sobre a realidade empírica; } \\
\text { - produção do conhecimento delimitada por seus campos de observação; } \\
\text { - constituída pela especificidade de seus objetos científicos e integração de seus } \\
\text { conceitos; } \\
\text { - regida por critérios lógico-matemáticos; } \\
\text { - produção científica operando num vazio histórico; } \\
\text { - levou a aplicação científico-tecnológica nas indústrias de forma reducionista, por } \\
\text { fragmentação do conhecimento; } \\
\text { - a unificação do conhecimento é determinada por suas aplicações técnicas; } \\
\text { - o método experimental se tornou ponte de união de diversos tipos de conhecimento e } \\
\text { forma de legitimação de todo conhecimento para fins práticos, e; } \\
\text { - assim, estabeleceu-se a necessidade de um vínculo entre construção teórica e objeto } \\
\text { do conhecimento, o que reduziu a ciência a um saber direcionado à transformação, } \\
\text { dominação e controle de objetos reais. }\end{array}$ \\
\hline
\end{tabular}

Quadro 2 - Classificação do conhecimento ambiental.

Fonte: Elaboração com base em Leff, 2001.

REAd - Edição 69 - Nº 2 - maio/agosto 2011 - p. 451-479 


\section{O DEBATE AMBIENTALISTA, AS RESEXs E O EXTRATIVISMO}

As Reservas Extrativistas (RESEXs) constituem uma categoria de Unidade de Conservação da Natureza, criada inicialmente no Estado do Acre, para a manutenção de comunidades de seringueiros e de áreas florestais ocupadas tradicionalmente por elas. Esse novo modelo de ocupação da terra foi inspirado nas Terras Indígenas, concebido no interior do movimento seringueiro, com forte influência de Chico Mendes. A criação das RESEXs contou também com a mobilização das comunidades habitantes das florestas amazônicas, as quais, entre outras, englobam extrativistas, ribeirinhos e indígenas, enfim, os "povos da floresta”, que constituíram famílias na região ao longo dos séculos e décadas passadas. O processo de criação das RESEXs obteve o apoio de intelectuais e de organizações nãogovernamentais (ONGs) nacionais e internacionais (ALEGRETTI, 1997; GONÇALVES, 2003; ALMEIDA, 2004).

As vertentes ambientalistas e as formas de conhecimento parecem estar relacionadas com a criação e a gestão das RESEXS. Existem defensores e opositores dessa categoria de Unidade de Conservação (UC) e o centro do debate está localizado na sua aptidão ou não para a conservação e também para a sobrevivência das populações locais.

O papel histórico-cultural e social das RESEXs foi reconhecido por Gonçalves (2003), Alegretti (1997), D’antona (2003) e Almeida (2004), entre outros, com destaque para a garantia do direito à terra e ao uso de seus recursos, bem como da construção de uma identidade positiva para o extrativista, responsável pela elevação de sua auto-estima: a de protetor da floresta. No aspecto socioeconômico, os resultados para algumas unidades pesquisadas são favoráveis à manutenção das famílias; verificou-se que o auto-consumo somado à produção comercializada apresenta aumento de renda substancial para as mesmas (CASTELO, 2000; MACIEL, 2003).

Esse caráter inovador de inclusão social e econômica é motivo de contestação dos ambientalistas preservacionistas (ou conservacionistas clássicos) que concebem o modelo de ilhas de conservação isoladas da presença humana como o mais adequado, desconsiderando aspectos como justiça social ou mesmo a importância da presença humana para desenvolvimento ecossistêmico.

Para Pádua (2006), as RESEX não têm nenhuma vinculação com a conservação e, dessa forma, são inadequadas como modelo de UC; são criadas apenas para fins sociais e econômicos, para inclusão das comunidades residentes. Pádua ainda se refere ao processo de união entre seringueiros e ambientalistas como mera estratégia de Chico Mendes para REAd - Edição 69 - No 2 - maio/agosto 2011 - p. 451-479 
Ambientalismo e concepções de RESEX, extrativismo e conhecimento no ICMBIO na Amazônia Legal

assegurar o direito à posse das áreas por eles habitadas historicamente. Nesta mesma linha, Olmos (2007) destaca que há fartura de estudos comprovando a "extinção em massa" de espécies em RESEX, embora não mencione tais estudos.

A ausência de informação e diagnósticos sobre as RESEXs e as UCs, de modo geral, contribuem para a desinformação e difusão de preconceitos ou de informações distorcidas com base em conflitos localizados. O uso político dos meios de comunicação pelas linhas ambientalistas contrárias ao modelo, e por interesses de grupos ruralistas contrários à reforma agrária e à conservação, difundem fatos isolados e/ou descontextualizados que tendem a menosprezar a legitimidade do modelo de unidade de conservação.

Dessa análise é possível extrair três tipos de visões de RESEX:

a) RESEX como UC de uso sustentável, conciliando conservação e justiça social (BRASIL, 2000; MEDEIROS, 2006; GONÇALVES, 2003; ALEGRETTI, 1997; IBAMA, 2007; ALMEIDA, 2004);

b) RESEX servindo à reforma agrária, cujos objetivos estão vinculados essencialmente à questão da posse da terra, excluindo a questão da conservação (PÁDUA, M., 2006; OLMOS, 2007); e,

c) RESEX oportunista, onde a questão da conservação serve apenas de pretexto para a posse da terra e obtenção de benefícios políticos e econômicos (PÁDUA, M., 2006; OLMOS, 2007).

As visões de RESEXs têm uma estreita relação com as concepções sobre extrativismo. Campos (2006) argumenta que o extrativismo na Amazônia não se resume à coleta, e que as comunidades locais não são avessas ao progresso técnico. Para ele, a importância do conhecimento local está na capacidade de gerar novas tecnologias, ultrapassando a simples aquisição do conhecimento formal, científico e transferível, determinado por um paradigma tecnológico. Um estudo realizado com técnicos governamentais, militares, líderes de movimentos e instituições sociais resultou na conclusão de que a atividade extrativista é a principal vocação para a região amazônica, devendo, no entanto, incorporar tecnologia e eficiência operacional que possam gerar competitividade (SÁ; VASQUEZ, 2001). Estudos de Maciel (2003), Campos (2006) e Andrade (2003) destacam iniciativas e oportunidades nesta direção, tais como o uso da biotecnologia, as ilhas de alta produtividade e a produção de couro vegetal. Por isso, Becker (2005) defende que a floresta só será preservada se produzir valor econômico para competir com a madeira, a pecuária e a soja, cabendo à Ciência, Tecnologia e Inovação um papel primordial na sustentabilidade ecossistêmica.

REAd - Edição 69 - Nº 2 - maio/agosto 2011 - p. 451-479 
No âmbito econômico, a crítica mais contundente à proposta do extrativismo na Amazônia é encontrada na análise de Homma (2000), segundo a qual o setor extrativo compreende um ciclo econômico de três fases distintas: aumento da extração, associado a um crescimento da demanda; a capacidade de aumentar a oferta chega ao limite, em face dos estoques disponíveis e do aumento no custo da extração; e, a extração começa a declinar em função da entrada no mercado do produto domesticado.

Em posição oposta, Campos (2006, p. 8) argumenta que

[...] o extrativismo na Amazônia pode ser compreendido como simples coleta de recursos naturais, dissociada do cultivo, da criação e do beneficiamento dos produtos. Mais além, o extrativismo se insere na cultura das populações locais, numa forma de vida harmoniosa com a natureza. Por outro lado, tais estruturas produtivas não são avessas a progresso técnico, o que poderia elevar-lhes a produtividade, propiciando uma nova alternativa econômica: o neo-extrativismo [...]

Atualmente, na Amazônia brasileira, o extrativismo é diferente do tradicionalmente praticado. É um conjunto de atividades econômicas de grupos sociais, não excluindo a incorporação de tecnologias nem os processos transformativos de comercialização e de agregação de valor aos produtos; abrange atividades agropastoris, extrativas e silviculturais (IBAMA, 2007).

Essa variação do entendimento do que vem a ser extrativismo foi consolidada no que veio a ser batizado neo-extrativismo, que decorre da busca de alternativas produtivas pelos extrativistas, procurando a inserção em novos mercados devido à decadência ou excesso de concorrência de mercados para os recursos anteriormente explorados.

Portanto o extrativismo, assim como as RESEX, é objeto de oposição dos conservacionistas clássicos. Para Pádua M. (2006) e Olmos (2007) o extrativismo é uma atividade falida, vista também como oportunista, onde o título de extrativista é utilizado apenas para obter benefícios de políticas públicas.

Considerando as diversas posições registradas na literatura, é possível retirar visões sobre extrativismo:

a) Extrativismo legítimo: viável economicamente com investimentos e tecnologias adequadas, responsável pela sobrevivência das comunidades que o praticam (CASTELO, 2000; MACIEL, 2003; CAMPOS, 2006; IBAMA, 2006; SÁ, VASQUEZ, 2001; BECKER, 1999).

b) Extrativismo falido: não gera renda suficiente para seus praticantes (HOMMA, 2000; PÁDUA, M., 2006; OLMOS, 2007); e, 
Ambientalismo e concepções de RESEX, extrativismo e conhecimento no ICMBIO na Amazônia Legal

c) Extrativismo oportunista: manutenção do status de extrativista como mera justificativa para angariar recursos financeiros e políticos pelos supostos praticantes do extrativismo (PÁDUA, M., 2006; OLMOS, 2007).

\section{PROCEDIMENTOS METODOLÓGICOS}

Foi realizada pesquisa descritiva com delineamento do tipo levantamento e perspectiva transversal (SELLTIZ et al., 1974; KERLINGER, 1979). O método utilizado foi o comparativo com partições cruzadas verificando similaridades e dissimilaridades de grupos de respondentes sobre vertentes ambientalistas, visões de conhecimento, RESEX e extrativismo.

A população foi composta por técnicos e analistas de nível superior que atuam na Amazônia Legal (estados do Acre, Amapá, Amazonas, Mato Grosso, Pará, Rondônia, Roraima e Tocantins e parte do estado do Maranhão), mais especificamente aqueles vinculados às diretorias/coordenações que trabalham diretamente com as UCs. Foram enviados questionários para todos os analistas ambientais, técnicos ambientais e funcionários contratados com formação superior, designados nesta pesquisa de "técnicos" ou "funcionários" do ICMBIO, constantes nas listas fornecidas pelos chefes dos Núcleos de Unidades de Conservação das representações regionais

As variáveis e respectivas componentes escolhidas para o estudo foram:

\section{Vertentes Ambientalistas:}

- Preservacionismo: Natureza versus Homem, Legislação à Risca, Retaguarda econômica, Sacralidade das espécies, Biocentrismo e Biodiversidade Integral.

- Sustentabilismo: Manejo Tecnológico, Serviços ambientais, Natureza-MercadoSociedade, Agenda 21, Custos-benefícios ambientais e Biodiversidade Utilitarista.

- Socioambientalismo: Homem-Natureza, Comunidades nas UCs, Mística-Religião, Sócio-Diversidade, Correção Legislativa e Biodireitos Comunitários.

\section{Visões do Conhecimento:}

- Anarquista ou Relativista Epistemológico: Supremacia da Tradição, Culpabilidade da Ciência, Democracia Plena.

- Diálogo dos Saberes ou Saber Ambiental: Princípio da Tradição, Diálogo da Ciência e Tradição e Ciência e Democracia. 
Daniel Santos Menezes. Osmar Siena \& Tomás Daniel Menéndez Rodríguez

- Científica Interdisciplinar: Diálogo Interdisciplinar, Racionalidade Pragmática e Democracia Condicionada.

- Científica Pura ou Positivista: Disciplinas Isoladas, Lógica-Matemática e Autoritarismo Científico.

\section{Visões de RESEX:}

- RESEX Oportunista.

- RESEX Agrária.

- RESEX UC.

\section{Visões do Extrativismo:}

- Extrativismo Oportunista

- Extrativismo Falido

- Extrativismo Legítimo

Para levantamento dos posicionamentos dos respondentes em relação ao ambientalismo, conhecimento, RESEXS e extrativismo, foi confeccionado questionário com afirmativas utilizando escala do tipo Likert para obter o grau de concordância para com afirmações representativas das diferentes visões. O questionário foi disponibilizado on-line.

Foram enviadas mensagens por meio eletrônico (mails) para 250 endereços de técnicos do ICMBIO dos estados da Amazônia Legal, fornecidos pelo Órgão pesquisado, 30 dos quais não foram recebidas pelos destinatários, totalizando 220 endereços ativos. Deste total, 91 questionários foram preenchidos, correspondendo a 36,4 do total de indivíduos ou 41,4\% dos indivíduos localizados. Dez (10) questionários foram excluídos por preenchimento insuficiente ou errôneo. Assim, a análise envolveu 81 questionários respondidos integral e corretamente, correspondendo a 36,8\% dos indivíduos localizados, cujo perfil está expresso na Tabela 1. Considerando o número total de respondentes em relação ao total de indivíduos localizados, a pesquisa realizada é representativa da população com probabilidade próxima de $80,0 \%$ e com margem de erro de $5 \%$, fato que é considerado uma limitação do trabalho.

Destaca-se também a expressiva participação de funcionários com até três e entre três e seis anos na função, consequência do fortalecimento do quadro de profissionais do Órgão, devido aos primeiros concursos públicos realizados na história do IBAMA, agora transferidos para o ICMBIO. Este fato pode ser motivo de viés dos resultados, especialmente quando analisados tendo por referência a lotação dos técnicos, uma vez que a posição dos mesmos pode não representar a visão consolidada na Unidade, mas refletir mais decisivamente a influência da formação acadêmica e/ou experiência anterior. 
Ambientalismo e concepções de RESEX, extrativismo e conhecimento no ICMBIO na Amazônia Legal

Foi realizada análise descritiva sobre o posicionamento dos técnicos do ICMBIO em relação às vertentes ambientalistas. Em seguida, foi utilizada a análise fatorial para identificação dos componentes que explicam a maior parte do fenômeno analisado, o que possibilitou uma compreensão do relacionamento entre as variáveis obtidas. Por contar com indicadores baseados em média e outros em valores absolutos, realizou-se, primeiramente, a padronização dos dados. O método de extração foi a Análise de Componentes Principais (ACP) e o método de rotação Varimax com normalização de Kaiser. O software SPSS versão 16.0 foi utilizado para essa análise.

Após a seleção dos principais fatores que emergiram da análise inicial, foi realizada a classificação dos técnicos em categorias, utilizando análise de agrupamento pelo método hierárquico aglomerativo, agrupando os respondentes por proximidade de posicionamentos. Nesta etapa, o software utilizado foi o XLSTAT, versão 2008.1.03, pelo Método de Agrupamento de Ward, o qual utiliza o cálculo da distância euclidiana como medida de proximidade. O produto final foi a identificação da favorabilidade dos técnicos para com as componentes do socioambientalismo e seu agrupamento em: técnicos favoráveis ao socioambientalismo, socioambientalismo moderado (sócio-moderados) e opositores ao socioambientalismo (sócio-opositores).

A partir da classificação dos grupos em relação às componentes do socioambientalismo, foi realizada a análise para verificar a distribuição dos servidores segundo as varáveis de controle escolhidas: lotação do servidor, formação acadêmica e estado de exercício.

\section{DADOS E DISCUSSÃO DOS RESULTADOS}

A maioria dos respondentes é graduada na área de ciências biológicas e saúde, seguidos daqueles formados na área de ciências agrárias e da terra, ciências humanas e sociais e exatas e tecnológicas. Não houve respondente formado em ciências administrativas, indicando uma carência de técnicos desta área o que, a princípio, pode dificultar trabalhos relacionados à gestão das UCs.

Em relação a técnicos com pós-graduação, também predomina a área de ciências biológicas e saúde, prevalecendo a formação no nível de especialização. Assim, 65,4\% dos técnicos têm no mínimo especialização o que pode contribuir para a iniciativa e o 
desenvolvimento de projetos consistentes e fundamentados em levantamentos e pesquisas de maneira sistemática.

A distribuição de respondentes por diretoria (DIPI - 45,7\%; DIUSP/CGFN - 25,9\%; DIUSP/CGRES - 28,4\%) está de acordo com a proporção da área de cobertura das UCs federais que segundo dados do Instituto Sócio-Ambiental (ISA, 2008), atinge 48,9\% de UCs de proteção integral e 51,1\% de UCs de uso sustentável.

\subsection{Posicionamentos dos Técnicos em Relação às Variáveis Estudadas}

No gráfico 1 é apresentada a distribuição de frequência relativa de concordância/indiferença/discordância segundo as vertentes ambientalistas.

Em termos gerais, a maior concordância para com as afirmações representativas dos fatores das vertentes foi observada para o preservacionismo, seguido do sustentabilismo e, por último, o socioambientalismo. Os resultados indicam presença das três vertentes no ICMBIO, embora a concordância com as posições do socioambientalismo não tenha superado a soma da discordância e da indiferença, demonstrando menos aderência dos técnicos para com esta vertente. O preservacionismo é a corrente mais presente. No entanto, parte dos respondentes que concorda que seus preceitos incorporam também preceitos das outras vertentes.

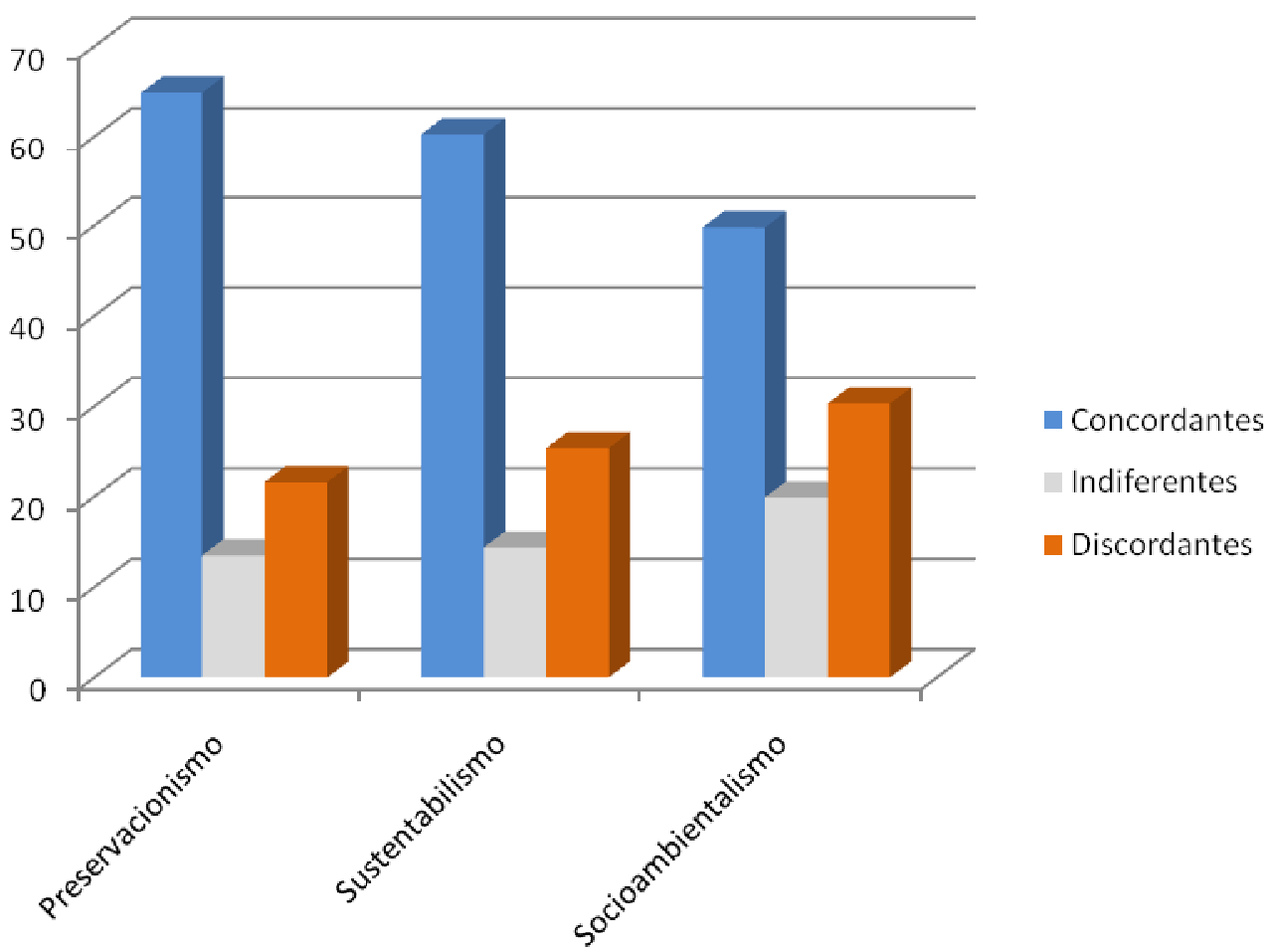


Ambientalismo e concepções de RESEX, extrativismo e conhecimento no ICMBIO na Amazônia Legal

\section{Gráfico 1 - Frequência relativa (\%) de concordância com as vertentes ambientalistas no ICMBIO da Amazônia Legal.}

Fonte: Elaboração dos autores.

Resultados semelhantes foram obtidos sobre visões do conhecimento, onde predomina a visão dialógica (73\%), seguida da sistêmica (60\%), da anárquica (43\%) e da ciência pura (34\%). Para as visões de RESEXs, predomina sua efetividade enquanto Unidade de Conservação (47\%), com as demais visões recebendo percentuais abaixo de $22 \%$. O entendimento do extrativismo como atividade econômica legítima e não falida prevalece, com $50 \%$ das respostas, enquanto as demais visões restaram abaixo de $23 \%$.

Para reduzir o número de variáveis e obter uma maior compreensão da variação de posicionamentos, foram realizadas a análise fatorial e a análise de clusters hierárquicos.

Os agrupamentos foram gerados a partir dos dados da tabela 1.

Foi possível identificar três fatores ou componentes que agrupam as variáveis em estudo.

1) Primeiro - componente Socioambiental: Socioambientalismo, Visão Anárquica e Visão Dialógica do Conhecimento, RESEX UC e Extrativismo Legítimo;

2) Segundo - componente Anti-RESEX: RESEX Agrária, RESEX Oportunista, Extrativismo Falido, Extrativismo Oportunista e;

3) Terceiro - componente Ambientalismo Consolidado: Preservacionismo, Sustentabilismo e Visão Interdisciplinar e Pura do Conhecimento.

Tabela 1 - Matriz de componentes segundo método de rotação Varimax com normalização de Kaiser.

\begin{tabular}{|c|c|c|c|}
\hline \multirow[b]{2}{*}{ Variáveis } & \multicolumn{3}{|c|}{ Componentes } \\
\hline & 1 & 2 & 3 \\
\hline Preservacionismo & ,009 & ,267 & 5,562 \\
\hline Sustentabilismo &, 347 &,- 513 &, 507 \\
\hline Socioambientalismo &, 814 &,- 286 &,- 064 \\
\hline Anárquica & ,894 &, 030 & 033 \\
\hline Dialógica & ,827 &,- 310 &, 000 \\
\hline Interdisciplinar &,- 126 & ,009 & ,831 \\
\hline Pura &,- 123 & 229 & ,836 \\
\hline RESEX Agrária &,- 415 &, 567 &, 160 \\
\hline RESEX Oportunista &,- 343 &, 555 & ,379 \\
\hline RESEX UC &, 589 &,- 454 &,- 157 \\
\hline Extrativismo Falido &,- 304 &, 733 & ,026 \\
\hline Extrativismo Legítimo &, 470 &,- 314 &,- 265 \\
\hline Extrativismo Oportunista &,- 031 &, 812 & ,336 \\
\hline
\end{tabular}

Fonte: Elaboração dos autores. 
O gráfico 2 ilustra a análise no plano tridimensional. Os três agrupamentos de variáveis resultantes (componentes) explicam, cumulativamente, 63,76\% da variância total. A componente número 1 (um) isoladamente explica $38,96 \%$ da variância, seguido da componente $2(16,48 \%)$ e da componente $3(8,36 \%)$.

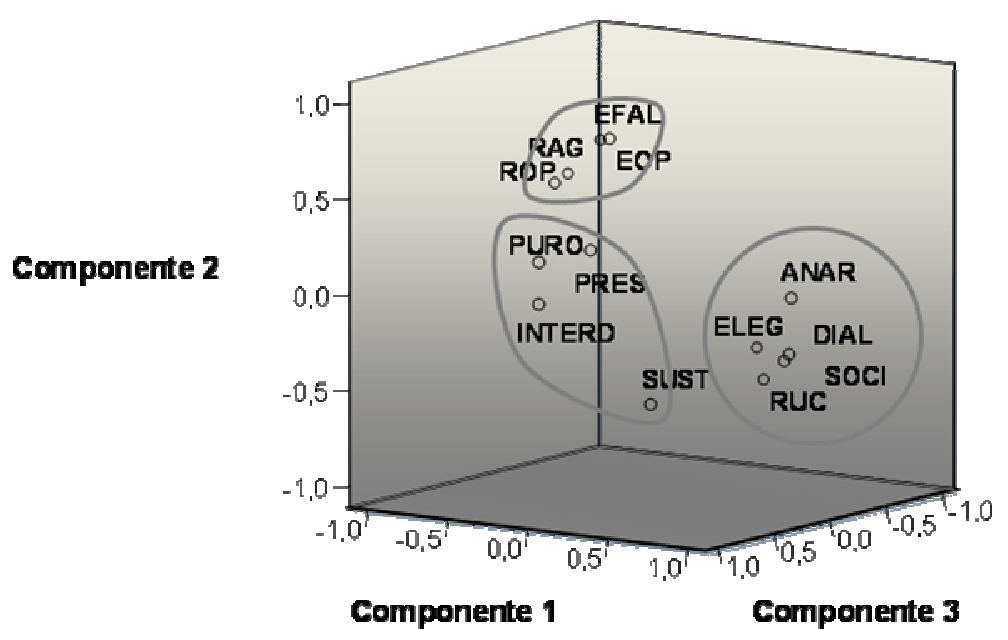

Gráfico 2 - Componentes Principais.

Fonte: Elaborado pelos autores.

O principal fator ou componente identificada, Socioambientalismo, Visão Anárquica, Visão Dialógica, Extrativismo Legítimo e RESEX UC corresponde à visão que reconhece a importância e o direito das populações tradicionais e sua inserção nas políticas direcionadas à preservação das unidades de conservação.

\subsection{Classe de Respondentes do Primeiro Grupo - Visão Socioambientalista}

A confecção de clusters hierárquicos com as variáveis desse grupo resultou no agrupamento de respondentes por semelhanças de posicionamentos em três classes, conforme dados da tabela 2, às quais foram denominadas:

- Classe 1 - Técnicos Favoráveis ao Socioambientalismo

- Classe 2 - Técnicos Socioambientalistas Moderados.

- Classe 3 - Técnicos Opositores ao Socioambientalismo. 
Ambientalismo e concepções de RESEX, extrativismo e conhecimento no ICMBIO na Amazônia Legal

Tabela 2 - Freqüência de Concordância por Classe do Agrupamento Hierárquico no ICMBIO da Amazônia Legal - 2008.

\begin{tabular}{lccc}
\hline Classe & Concordância & Discordância & Indiferença \\
\hline Classe 1 & $90 \%$ & $0 \%$ & $10 \%$ \\
Classe 2 & $60 \%$ & $13 \%$ & $27 \%$ \\
Classe 3 & $24 \%$ & $56 \%$ & $20 \%$ \\
\hline
\end{tabular}

Fonte: Elaboração dos autores.

A frequiência relativa para os favoráveis ao socioambientalismo foi de $39 \%$ das respostas dos servidores, para os sócio-moderados, 25\%, e para os opositores ao socioambientalismo, $36 \%$, conforme gráfico 3 .

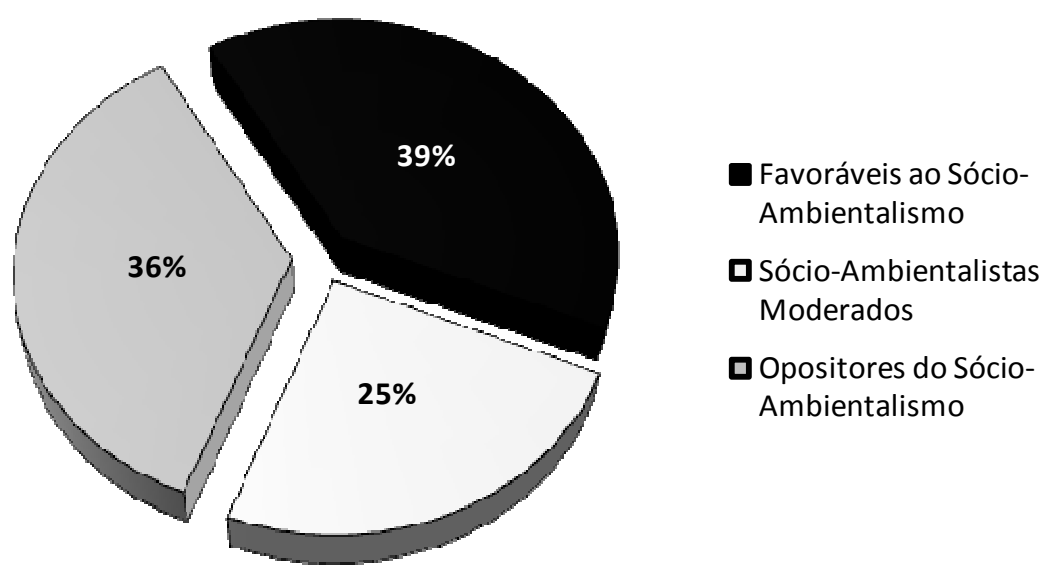

Gráfico 3 - Freqüência Relativa de Respondentes por Classes de Favorabilidade ao Socioambientalismo no ICMBIO da Amazônia Legal, 2008.

Fonte: Elaboração dos autores.

A distribuição por classes demonstra, assim, uma polarização de visões no âmbito do Instituto a respeito do socioambientalismo, com servidores favoráveis, moderados e em oposição às concepções dessa vertente.

\subsection{Classes por Diretoria/Coordenação}

A distribuição dos servidores das diretorias pelas classes de posicionamento está expressa no gráfico 4. Na Diretoria de Proteção Integral (DIPI), 40\% dos respondentes são contrários aos aspectos ligados ao socioambientalismo, 38\% favoráveis e $22 \%$ moderados. 
Essa preferência, embora não muito expressiva, era esperada pela maior concordância verificada nessa unidade com as concepções do preservacionismo e a gestão de UCs de proteção integral.

Na Coordenação Geral de RESEX e Desenvolvimento Sustentável (CGRES), 43\% são favoráveis ao socioambientalismo, mas $43 \%$ são opositores às concepções dessa vertente. Nessa coordenação era esperado um maior número de favoráveis ao socioambientalismo, dados seus objetivos e linha de atuação socioambiental. Essa divisão dos técnicos entre duas concepções pode ser vista como elemento que impõe dificuldades para o andamento dos trabalhos voltados para as RESEX e RDS ou um contrabalanceamento desejável, dependendo de como o órgão encara a gestão de eventuais conflitos decorrestes deste fato.

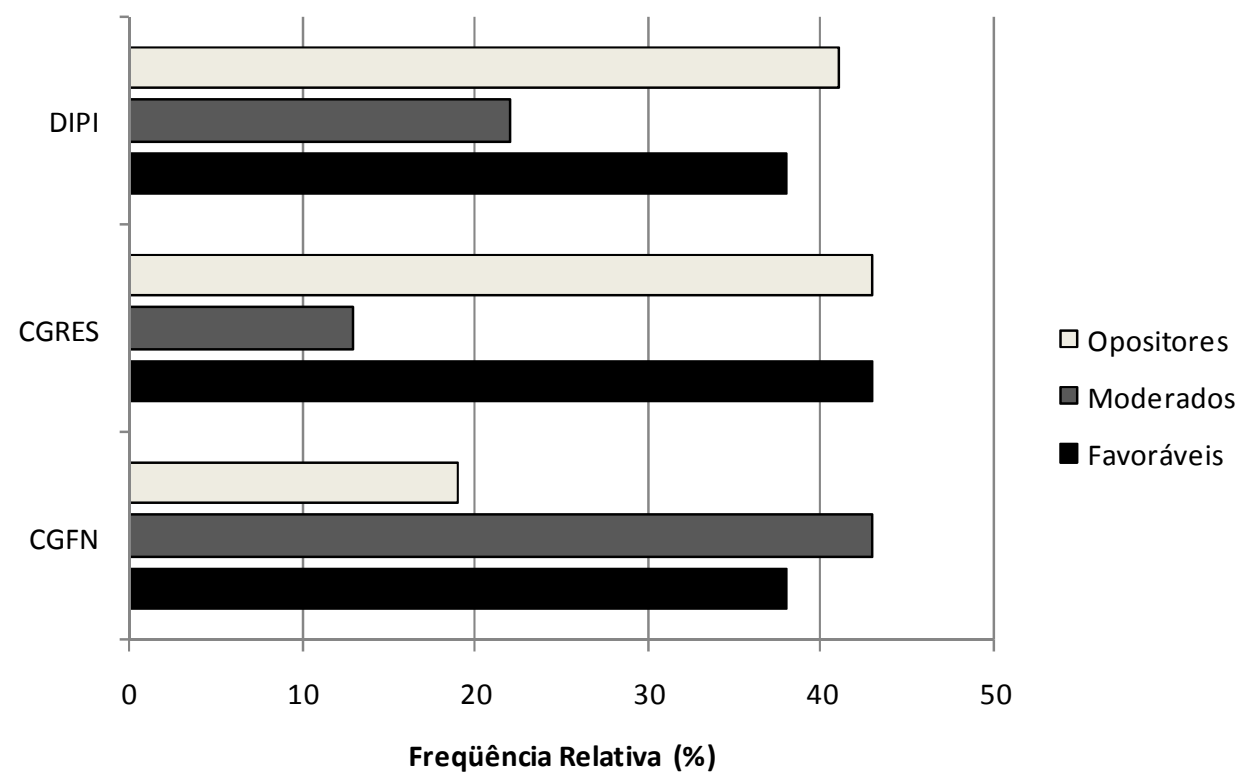

Gráfico 4 - Freqüência Relativa de Respondentes por Diretoria e Coordenação Distribuídos segundo Classe de Favorabilidade ao Socioambientalismo no ICMBIO da Amazônia Legal - 2008.

Fonte: Elaboração dos autores.

$\mathrm{Na}$ Coordenação Geral de Florestas Nacionais (CGFN) foi encontrada uma predominância de respostas com as concepções do socioambientalismo moderado. Este resultado era esperado, pois a atuação da unidade é mais direcionada ao manejo florestal, perspectiva esta que, em consonância com Zhouri (2006), está vinculada ao sustentabilismo. Nessa linha, pode-se vislumbrar o manejo dos recursos naturais e a presença humana, mas com a preponderância do tecnicismo científico. 
Ambientalismo e concepções de RESEX, extrativismo e conhecimento no ICMBIO na Amazônia Legal

\subsection{Classes por Áreas de Formação}

O gráfico 5 apresenta a distribuição das visões sobre o socioambientalismo pelas áreas de formação na graduação. No grupo graduado em ciências biológicas e saúde, que congrega a maior parte $(53 \%)$ dos técnicos consultados, a maioria manifesta posição contrária ao socioambientalismo, o que corrobora em parte a análise de Martinez-Alier (2007) e Guha (2000), pois também se manifesta uma considerável expressão de sócio-favoráveis.

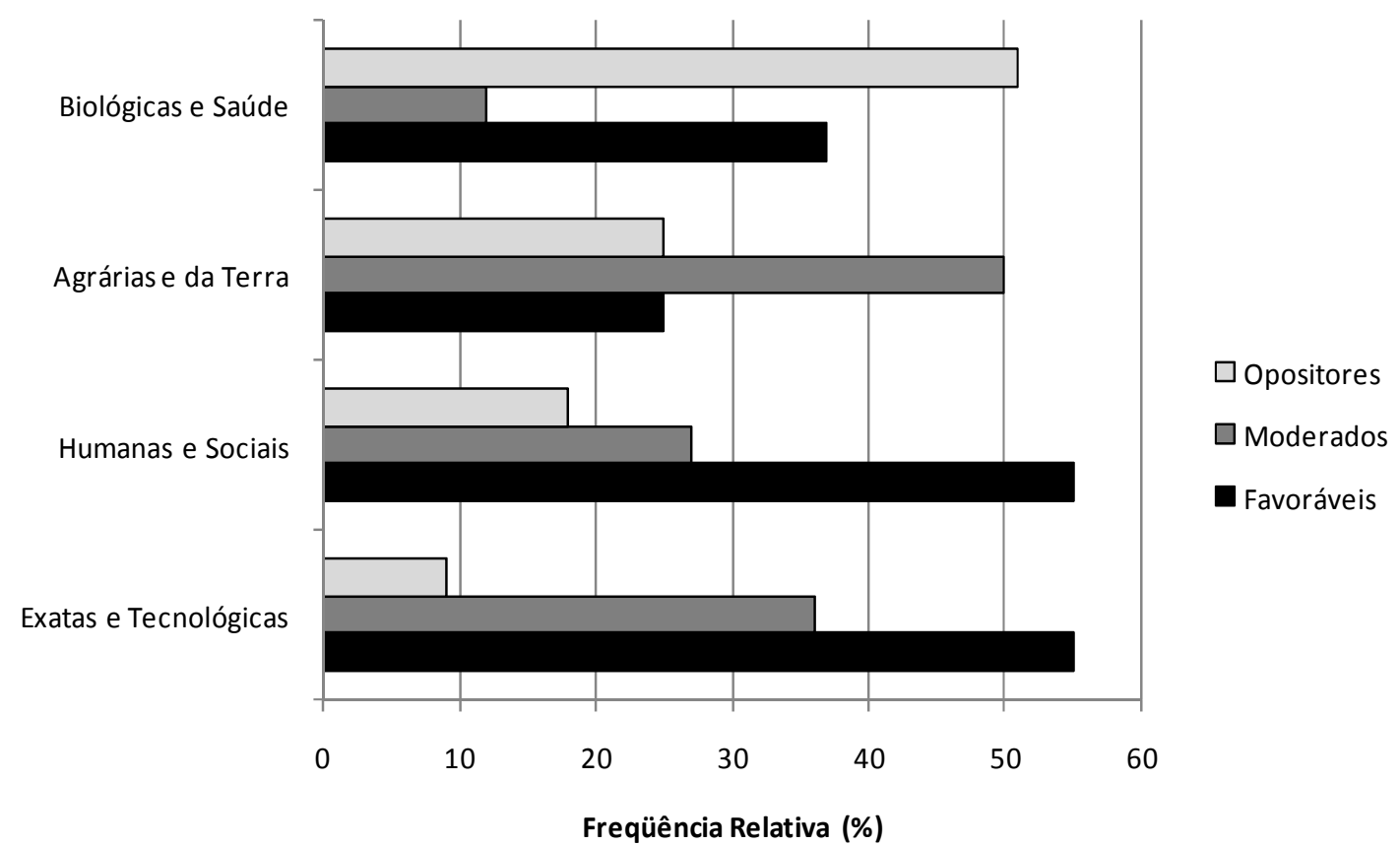

Gráfico 5 - Freqüiência Relativa de Respondentes por Curso de Graduação segundo Classes de Favorabilidade ao socioambientalismo no ICMBIO da Amazônia Legal 2008.

Fonte: Elaboração dos autores.

Para o grupo graduado nas áreas de ciências agrárias e da terra, metade dos respondentes pode ser associada à posição sócio-moderada. Nos grupos formados em ciências exatas e tecnológicas e ciências humanas e sociais predominaram as posições favoráveis ao socioambientalismo.

\subsection{Classes e Áreas dos Cursos de Pós-Graduação}

No cruzamento das classes de posicionamentos com a formação na pós-graduação dos respondentes, expresso na tabela 3 , foi constatado que os técnicos pós-graduados em ciências REAd - Edição 69 - Nº 2 - maio/agosto 2011 - p. 451-479 
humanas e sociais são favoráveis ao socioambientalismo (sócio-favoráveis). Metade dos técnicos pós-graduados em ciências biológicas e saúde manifestou posição contrária ao socioambientalismo (sócio-opositores). Os pós-graduados nas demais áreas e aqueles que não possuem pós-graduação podem ser localizados como socioambientalistas moderados.

Tabela 3 - Pós-Graduação dos respondentes segundo classe sócio-ambientalista no ICMBIO da Amazônia Legal - 2008.

\begin{tabular}{lccc}
\hline Área de concentração & $\begin{array}{c}\text { Sócio-favoráveis } \\
\mathbf{( \% )}\end{array}$ & $\begin{array}{c}\text { Sócio- } \\
\text { moderados } \\
\mathbf{( \% )}\end{array}$ & $\begin{array}{c}\text { Sócio-opositores } \\
\mathbf{( \% )}\end{array}$ \\
\hline Dos Cursos & 23 & 62 & 15 \\
Bióriás e da terra & 38 & 12 & 50 \\
Outras áreas & 58 & 51 & 21 \\
Não possuide & 56 & 4 & 40 \\
\hline
\end{tabular}

Fonte: Elaboração dos autores.

Assim, pode-se dizer que os pós-graduados em ciências biológicas possuem uma disposição maior para preservação dos ecossistemas livres da presença humana, desfavorável à participação efetiva das Populações Tradicionais e à valorização do conhecimento tradicional nas políticas de conservação ambiental, em consonância com a análise de Martinez-Alier (2007), Guha (2000) e Colchester (2000).

\subsection{Classes e Estados de Exercício}

Os servidores lotados nos estados do Acre, Amazonas, Maranhão, nos quais a atividade extrativista é mais destacada, junto com Tocantins, manifestam maior concordância com o socioambientalismo. No Amapá houve igual distribuição entre favoráveis e opositores ao socioambientalismo. Em Roraima, prevalece a posição moderada.

Nos estados que ainda apresentam altas taxas de desmatamento anual - Pará, Rondônia e Mato Grosso - predominam os opositores ao socioambientalismo. Nesses estados, onde estão localizadas as pressões mais intensas das atividades econômicas relacionadas ao uso intensivo da terra, parece haver uma tendência maior ao preservacionismo por parte dos técnicos do órgão ambiental. Este fato pode ser devido ao reflexo do clima de alerta gerado no quadro IBAMA/ICMBIO contra qualquer tipo de desmatamento, com investimentos em ações de combate, direcionadas pela direção central. Além disso, existe a atuação de organismos internacionais, com princípios consoantes com o sustentabilismo, conforme a análise efetuada 
Ambientalismo e concepções de RESEX, extrativismo e conhecimento no ICMBIO na Amazônia Legal

por Zhouri (2006), relegando ao segundo plano a participação e autodeterminação das comunidades locais.

\section{CONCLUSÕES}

Os resultados indicam a presença das três vertentes ambientalistas no ICMBIO, embora a concordância com as posições do socioambientalismo não tenha superado a soma da discordância e da indiferença, o que aponta para uma menor aderência dos técnicos para com esta vertente. O preservacionismo é a corrente mais presente, mas parte dos técnicos do ICMBIO que concordam com seus preceitos também incorpora preceitos das outras vertentes. Assim, os resultados apontam para um ambientalismo "misto", composto por uma visão plural do ambientalismo ou na perspectiva de um ambientalismo em processo de formação; indefinido em alguns pontos, com tendência a englobar uma ampla gama de características, inclusive algumas contraditórias ou excludentes quando analisadas sob a ótica das vertentes de origem. Assim, não há uma visão unânime a respeito do ambientalismo no Instituto Chico Mendes na Amazônia Legal. Também não existem linhas ambientalistas puras, mas compostas por preceitos de várias vertentes.

As visões de RESEXs e do extrativismo estão relacionadas com o socioambientalismo, demonstrando que o modelo deste tipo de UC parece fazer parte, principalmente, dessa linha de pensamento. Além disso, parte dos técnicos de posicionamento socioambientalista moderado e opositores ao socioambientalismo manifestaram posições favoráveis a essa categoria de unidade de conservação, não excluindo de suas preferências as concepções socioambientalistas. Assim, os resultados apontam para certa diversidade e miscigenação das linhas ambientalistas, inclusive em relação ao socioambientalismo.

Foi constatado que os técnicos formados em certas áreas são mais inclinados para compreensões da relação homem-natureza e sobre políticas públicas adequadas à conservação. Da mesma forma, há indicações de diferença de visões conforme a diretoria/coordenação de procedência do servidor e o estado de exercício do mesmo.

Os grupos de formação acadêmica que demonstraram maior favorabilidade às componentes socioambientalistas foram de Ciências Humanas e Sociais, Exatas e Tecnológicas. O grupo formado em Ciências Agrárias e da Terra pode ser localizado numa posição moderada em relação ao socioambientalismo. No grupo formado em Ciências Biológicas e Saúde foi onde se verificou maior número de opositores ao socioambientalismo. REAd - Edição 69 - N² 2 - maio/agosto 2011 - p. 451-479 
$\mathrm{Na}$ Diretoria de Proteção Integral predomina a posição contrária ao socioambientalismo, o que pode dificultar a ação da unidade, pois os trabalhos dos técnicos com populações do entorno das Unidades de Conservação são freqüentes. Na Coordenação Geral de Reservas Extrativistas há uma divisão entre favoráveis e opositores ao socioambientalismo, o que pode gerar conflitos entre servidores e chefias em relação aos objetivos da coordenação. Na Coordenação Geral de Florestas Nacionais prevalece uma posição moderada.

A influência do contexto organizacional foi expressa na semelhança de posicionamentos dos servidores nos estados com altos índices de desmatamento, três deles componentes do chamado Arco de Fogo (PA, MT, RO). Nestes estados há um clima permanente de alerta ao desmatamento e queimadas, com muita concentração nas atividades de fiscalização e combate às ações antrópicas. Como a presença de populações tradicionais no entorno das UCs desses estados é uma realidade, a possibilidade de conflitos entre comunidades locais e o Órgão governamental é alta.

Nos estados com maior área preservada, onde a cultura extrativista também está mais presente, constata-se uma maior favorabilidade dos técnicos com a visão socioambientalista. Assim, parece haver a influência da cultura organizacional e do contexto local e regional na visão desses servidores. Uma mudança de cultura e / ou de contexto pode então favorecer a implementação dos objetivos socioambientais do ICMBIO.

No âmbito do ICMBIO a compreensão da diversidade ambientalista presente no corpo técnico é capaz de subsidiar abordagens alternativas no planejamento de ações. A compreensão de conflitos de idéias e interesses faz parte do diagnóstico para elaboração de políticas e configurações organizacionais e processos.

Pesquisas em outras regiões de atuação do ICMBIO para aprofundamento das diferenças e semelhanças entre os posicionamentos ambientalistas, como também a investigação em outros contextos, organizações e setores da sociedade, têm o potencial de contribuir significativamente para ampliação do conhecimento na área. Constitui também potencial para pesquisas futuras a detecção do grau de influência da concepção pessoal dos técnicos nos objetivos organizacionais.

\section{REFERÊNCIAS}

ALEGRETTI, Helena. Ambientalismo Político y Reforma Agrária: de Chico Mendes al movimiento de los sien tierra. Nueva Sociedad, n. 150, p. 57-68, Julio-Agosto, 1997.

ALMEIDA, Mauro W. Barbosa. Direitos à floresta e ambientalismo: seringueiros e suas lutas. Revista Brasileira de Ciências Sociais, vol. 19, n. 55, p.33-52, São Paulo: jun 2004. 
Ambientalismo e concepções de RESEX, extrativismo e conhecimento no ICMBIO na Amazônia Legal

ANDRADE, Alexandre Augusto Lopes Goulart. Artesãos da floresta, população tradicional e inovação tecnológica: o caso do "couro vegetal" na Reserva Extrativista do Alto Juruá, Acre. Dissertação de mestrado. UNICAMP, [s.n.], 2003.

BECKER, Bertha K. Cenários de curto prazo para o desenvolvimento da Amazônia. Cadernos do Núcleo de Apoio às Políticas Integradas para a Amazônia (NAPIAm), no 6. Secretaria de Coordenação da Amazônia. Brasília, outubro, 1999.

BECKER, Bertha K. Geopolítica da Amazônia. Estudos Avançados, 2005, vol.19, no. 53, p.71-86. Disponível em: < http://www.scielo.br/pdf/ea/v19n53/24081.pdf> . Acesso jun/2008.

BRASIL. Lei no 9.985 de 18 de julho de 2000. Diário Oficial da União. Brasília: 19 de julho de 2000.

BRASIL. Decreto no 6.100, de 26 de abril de 2007. Brasília: Diário Oficial da União de 27 de abril de 2007, 2007a.

BRASIL. Lei $\mathbf{n}^{0}$ 11.516, de 28 de agosto de 2007. Brasília: Diário Oficial da União de 29 de agosto de 2007, 2007b.

CAMPOS, Índio. A sustentabilidade da agricultura na Amazônia. Disponível em: < http://www.anppas.org.br/encontro anual/encontro1/gt/agricultura meio ambiente/Indio\%20Campos. pdf>. Acesso em junho de 2006.

CASTELO, Carlos Estevão Ferreira. Avaliação econômica da produção familiar na Reserva Extrativista Chico Mendes no Estado do Acre. Caderno de Pesquisas em Administração. São Paulo, v.1, n. $11,1^{\circ}$ trim, 2000.

COLCHESTER, 2000. Resgatando a natureza: comunidades tradicionais e modos de vida. In: DIEGUES, Antonio Carlos (Org.). Etnoconservação: novos rumos para a proteção da natureza nos trópicos. São Paulo: Hucitec, 2000.

D'ANTONA, Alvaro de Oliveira. Garantir a terra, garantia da terra? Reservas Extrativistas na Amazônia Legal brasileira. Tese de Doutorado. Universidade Estadual de Campinas. Campinas, 2003.

DIEGUES, Antonio Carlos (org.). Etnoconservação: novos rumos para a proteção da natureza nos trópicos. São Paulo: Hucitec, 2000.

DRUMMOND, José Augusto. A visão conservacionista (1920-1970). In: SVIRKY, Enrique; CAPOBIANCO, João Paulo R. Ambientalismo no Brasil: passado, presente e futuro. São Paulo: Instituto Sócio Ambiental: Secretaria do Meio Ambiente do Estado de São Paulo, 1997.

GONÇALVES, Carlos Walter Porto. Geografando nos varadouros do mundo: da territorialidade (o seringal) à territorialidade seringueira (a Reserva Extrativista). Brasília: IBAMA, 2003.

GUHA, Ramachandra. O biólogo autoritário e a arrogância do anti-humanismo. In: DIEGUES, Antônio Carlos (org.). Etnoconservação: novos rumos para a proteção da natureza nos trópicos. São Paulo: Hucitec, 2000.

HAJER, Maarten. Ecological modernization as cultural politics. In: LASH, S. (Org.). Risky, environment and modernity. London: Sage, 1996. p. 246-268.

REAd - Edição 69 - Nº 2 - maio/agosto 2011 - p. 451-479 
Daniel Santos Menezes. Osmar Siena \& Tomás Daniel Menéndez Rodríguez

HOMMA, Alfredo Kingo Oyama. Amazônia: os limites da opção extrativa. Ciência Hoje. v, 27, no 159, abril de 2000.

ISA. INSTITUTO SÓCIO-AMBIENTAL. Unidades de Conservação na Amazônia Legal: Cômputo Geral. Disponível em: <http://www.socioambiental.org/uc/quadro_geral>. Acesso em 24/06/2008.

IBAMA. INSTITUTO BRASILEIRO DO MEIO AMBIENTE E DOS RECURSOS NATURAIS RENOVÁVEIS. O Neoextrativismo ou Agroextrativismo. Disponível em: < http://www.ibama.gov.br/resex/textos/h12.htm>. Acesso em junho de 2006.

IBAMA. INSTITUTO BRASILEIRO DO MEIO AMBIENTE E DOS RECURSOS NATURAIS RENOVÁVEIS. Efetividade de gestão das unidades de conservação federais do Brasil. IBAMA, WWF-Brasil. - Brasília: IBAMA, 2007.

KERLINGER, Fred. Metodologia da pesquisa em ciências sociais. São Paulo: EPV-EDUSP, 1979.

KUHN, T. S. A estrutura das revoluções científicas. 9.ed. São Paulo: Perspectiva, 2006. LEFF, Enrique. Epistemologia ambiental. São Paulo: Cortez, 2001.

LENZI, Cristiano Luiz. Sociologia ambiental: risco e sustentabilidade na modernidade. Bauru, SP: Edusc, 2006.

MACIEL, Raimundo Cláudio Gomes. Ilhas de alta produtividade: inovação essencial para a manutenção dos seringueiros nas reservas extrativistas. Dissertação de mestrado. UNICAMP. Campinas, 2003.

MENEZES, Daniel S.; SIENA, Osmar. Ambientalismo no Instituto Chico Mendes de Conservação da Biodiversidade (ICMBIO) da Amazônia Legal. Revista Organizações \& Sociedade (O\&S), v. 17, nº 54, p.479-498, julho/setembro, 2010.

MARTINEZ-ALIER, Joan. O ecologismo dos pobres: conflitos ambientais e linguagens de valoração. São Paulo: Contexto, 2007.

MEDEIROS, Rodrigo. Evolução das tipologias e categorias de áreas protegidas no Brasil. Ambiente Sociedade. Jan./June 2006, vol.9, no. 1, p.41-64.

OLMOS, Fábio. As Reservas Extrativistas são Unidades de Conservação? O ECO. Disponível em: $<$ http://www.oeco.com.br/fabio-olmos/44-fabio-olmos/16765-oeco17657>. Acesso em 30/11/2007.

PÁDUA, José Augusto (org.). Ecologia e política no Brasil. Rio de Janeiro: Espaço e Tempo: IUPERJ, 1987.

PÁDUA, Maria Tereza Jorge. Instituto Chico Mendes. O ECO. 2006. Disponível em: http://arruda.rits.org.br/oeco/servlet/newstorm.ns.presentation.NavigationServlet?publicationCode $=6 \&$ pageCode $=78 \&$ textCode $=21814 \&$ date $=$ currentDate $\&$ contentType $=$ html\#topo. $\quad$ Acesso $\quad \mathrm{em}$ $28 / 06 / 2008$.

PEPPER, David. Ambientalismo moderno. Coleção Perspectivas Ecológicas. Lisboa: Instituto Piaget, 2000.

PORTO, Marcelo Firpo. Saúde do trabalhador e o desafio ambiental: contribuições do enfoque ecossocial, da ecologia política e do movimento pela justiça ambiental. Ciência e Saúde Coletiva. 10(4), 829-839, 2005. 
Ambientalismo e concepções de RESEX, extrativismo e conhecimento no ICMBIO na Amazônia Legal

RYLANDS, Anthony B.; BRANDON, Katrina. Unidades de conservação brasileiras. Megadiversidade. Vol.1, $\mathrm{n}^{\mathrm{O}} \quad 1$, julho $2005 . \quad$ Disponível em: http://www.brazadv.com/images/conservation_units.pdf. Acesso em 24/06/2008.

ROHDE, Geraldo Mario. Epistemologia ambiental: uma abordagem filosófico-científica sobre a efetuação humana alopoiética. Porto Alegre: EDIPUCRS, 1996.

SÁ, Rosa L. de, VASQUEZ, Regina (Coord.). Desenvolvimento e conservação do meio ambiente: pesquisa de opinião com lideranças e a população da Amazônia. Brasília: WWF, 2001.

SANTILLI, Juliana. Socioambientalismo e novos direitos: proteção jurídica à diversidade biológica e cultural. São Paulo: Peirópolis, 2005.

SANTOS, Boaventura de Souza (org.). Semear outras soluções: os caminhos da biodiversidade e dos conhecimentos rivais. Rio de Janeiro: Civilização Brasileira, 2005.

SARKAR, Sahotra. Restaurando o mundo selvagem. In: DIEGUES, Antonio Carlos (org.). Etnoconservação: novos rumos para a proteção da natureza nos trópicos. São Paulo: Hucitec, 2000.

SELLTIZ, Claire et al. Métodos de pesquisa nas relações sociais. São Paulo: EPV- EDUSP, 1974.

ZHOURI, Andréa. O ativismo transnacional pela Amazônia: entre a ecologia política e o ambientalismo de resultados. Horizontes Antropológicos. Porto Alegre, ano 12, n.25, p. 139-169, jan/jun, 2006.

\section{RESUMO}

O trabalho discute o posicionamento de técnicos de nível superior do Instituto Chico Mendes de Conservação da Biodiversidade (ICMBIO), em exercício na Amazônia Brasileira, em relação ao ambientalismo e identifica possíveis relações entre os posicionamentos e visões do conhecimento, concepção de Reserva Extrativista (RESEX) e de extrativismo. Consoante a base teórica discutida, foram adotadas as seguintes tipologias para as categorias estudadas: correntes ou vertentes ambientalistas: preservacionista, Sustentabilista e Socioambientalista; visões do conhecimento: anarquista, dialógica (ou saber ambiental); interdisciplinar; e, científica pura; visões de RESEX: RESEX como Unidade de Conservação (UC) de uso sustentável, RESEX servindo à reforma agrária e RESEX oportunista; visões sobre extrativismo: extrativismo legítimo, extrativismo falido e extrativismo oportunista. $\mathrm{O}$ método utilizado foi o comparativo com partições cruzadas, verificando similaridades e dissimilaridades de grupos de respondentes. Para levantamento dos posicionamentos dos respondentes foi disponibilizado a todos os técnicos um questionário com afirmações representativas das diferentes visões, utilizando escala do tipo Likert. Foi realizada a classificação dos técnicos em categorias, utilizando análise de agrupamento pelo método hierárquico aglomerativo, tendo como parâmetro a proximidade de posicionamento. Constatou-se que não há visão única a respeito do ambientalismo no Instituto Chico Mendes na Amazônia Legal e não existem linhas ambientalistas puras, mas compostas por concepções de várias vertentes. As visões sobre RESEXs e extrativismo estão relacionadas com concepções sociaombientalistas, reforçando a defesa de que este tipo de Unidade de Conservação faz parte dessa linha de pensamento.

Palavras-chave: Ambientalismo; Vertentes Ambientalistas; Reservas Extrativistas; Extrativismo; Conhecimento.

REAd - Edição 69 - Nº 2 - maio/agosto 2011 - p. 451-479 


\title{
ENVIRONMENTALISM AND CONCEPTIONS OF RESEX, EXTRACTIVISM AND KNOWLEDGE IN THE ICMBIO IN THE BRAZILIAN AMAZON
}

\begin{abstract}
The paper discusses the positioning of high level technicians the "Instituto Chico Mendes de Conservação da Biodiversidade (ICMBIO)", acting in the Brazilian Amazon, in relation to environmentalism and identifies possible relationships between the positioning and views on knowledge, conception of Extractive Reserve (RESEX ) and extractivism. According to the theoretical discussion, we make the following types for the studied categories: environmentalist slope: preservationist, sustainabilist and socio-environmentalist; views of knowledge: anarchist, dialogic (or environmental knowledge), interdisciplinary and pure science; views of RESEX: RESEX as Conservation Unit (UC) for sustainable use, RESEX serving the agrarian reform and opportunist RESEX; views on extractivism: legitimate extractivism, legitimate extractivism and opportunistic extractivism. The method used was a comparative cross-partition, checking similarities and dissimilarities of respondents groups. To survey the positions of the respondents was made a questionnaire available to all staff with statements representing different views, using Likert scale. It was done a classification into categories of technicians, using cluster analysis by the agglomerative hierarchical method, having as parameter the proximity of placement. It was found that no single view about environmentalism in the Chico Mendes in the Legal Amazon and there are not pure environmentalist lines, but composed of several strands of ideas. The views on RESEXs and extractivism are related concepts socio- environmentalism, reinforcing the argument that this type of conservation is a part this line of thought.
\end{abstract}

Keywords: Environmentalism; Environmentalist slope; Extractivist Reserve; Extractivism; Knowledge. 